\title{
AEROSOL-CLOUD INTERACTION DURING THE TRANSITION TIME PERIOD OF ARCTIC HAZE TO CLEAN SUMMER CONDITIONS
}

\author{
A. SCHWARZENBOECK ${ }^{1}$, C. DUROURE ${ }^{1}$, J.F. GAYET ${ }^{1}$, A. HERBER ${ }^{2}$, R. KRECJI ${ }^{4}$, R. LEFEVRE ${ }^{1}$, \\ A. MINIKIN ${ }^{5}$, R. NEUBER ${ }^{3}$, V. SHCHERBAKOV ${ }^{1}$, J. STROEM ${ }^{4}$, S. YAMAGATA $^{7}$, T. \\ YAMANOUCHI $^{6}$ \\ ${ }^{1}$ Laboratoire de Météorologie Physique, Université Blaise Pascal / CNRS , France \\ ${ }^{2}$ Alfred-Wegener-Institut für Polar- und Meeresforschung, Bremerhaven, Germany \\ ${ }^{3}$ Alfred-Wegener-Institut für Polar- und Meeresforschung, Potsdam, Germany \\ ${ }^{4}$ Department of Meteorology Stockholm University, Stockholm, Sweden \\ ${ }^{5}$ Deutsches Zentrum für Luft- und Raumfahrt, Institut für Physik der Atmosphäre, Wessling, Germany \\ ${ }^{6}$ National Institute for Polar Research, Tokyo, Japan \\ ${ }^{7}$ Hokkaido University, Graduate School of Engineering, Sapporo, Japan
}

Keywords: Arctic aerosol, aerosol-cloud interaction, arctic mixed phase clouds, indirect aerosol effect

\section{INTRODUCTION}

The transition from Arctic haze (a large amount of aerosols coming from Eurasian industrial areas accumulate over the Arctic and cover the Arctic by a layer of this smog-like haze of the size of the continent of Africa) to clean summer conditions is quite sharp due to a radical change in atmospheric transport patterns and is, thus, easy to identify. During Arctic summer, the high latitudes are more or less "protected" from long-range transport of air masses from lower latitudes. It is expected that the strong intrusion of polluted air masses during haze events are of specific interest for determining the anthropogenic influence on the radiative balance including aerosol-cloud interaction processes [Curry et al., 2000].

The findings of aerosol-cloud interactions in mixed-phase arctic clouds presented here are based on the ASTAR2004 (Arctic study of tropospheric aerosols, clouds and radiation) international measurement campaign, with in situ observations of detailed microphysical and optical cloud particle properties onboard the Polar-2 aircraft during the transition from polluted Arctic haze (observed especially in late winter, early spring months) to clean summer aerosol conditions. Simultaneously to cloud particle analysis on the research aircraft Polar-2, detailed aerosol characterisation was performed on a second aircraft Polar-4. The aircraft operations were conducted from the base of the project at Longyearbyen, Spitzbergen.

The principal scientific objective of the aerosol-cloud interaction aspect being part of ASTAR2004 focused in particular on the ice phase nucleation in Arctic mixed-phase clouds. Furthermore, our interest in this arctic experiment was dedicated to cloud-radiation interaction wherein we experimentally answer the question of how different ice crystal shapes govern the scattering phase function. Moreover, the in situ cloud measurements allow to develop an adequate strategy for the interpretation of remote sensing data from a depolarisation Lidar onboard the same aircraft (Polar-2).

To achieve the objectives, LaMP installed a unique combination of scientific instruments onboard the Polar-2 aircraft from AWI. This instrumental combination on the Polar-2 research aircraft comprised a (i) the Cloud Particle Imager (CPI, SPEC Inc.; [Lawson et al., 2001]) to record cloud particle microphysics and ice crystal morphology at high digital resolution (pixel size of $2.3 \mu \mathrm{m}$ ), (ii) the Polar Nephelometer developed and operated at LaMP [Gayet et al., 1997; Oshchepkov et al., 2000] to quantify the scattering phase function induced by these cloud particles, (iii) the Nevzorov Probe [Korolev et al., 
1998] to quantify separately IWC and LWC, and (iv) the classical PMS FSSP-100 and 2D-C probes to record the cloud particle size spectra.

\section{INSTRUMENTATION / METHODS / RESULTS}

The scientific objective of our purposes within ASTAR2004 focuses on the quantification of the impact of aerosol particle properties on the cloud particle properties in the Arctic in collaboration with ITM Stockholm and IPA-DLR Oberpfaffenhofen. This quantification is done after experimental characterization of detailed microphysical and optical properties of Arctic mixed-phase clouds which leads in particular to the study of the ice phase initiation and the role of the ice phase in cloud-radiation interaction, and thus, the indirect aerosol effect.

In detail, our study of the microphysical and optical cloud properties on aircraft Polar-2 is related to the physico-chemical and optical properties of the aerosol particles simultaneously analysed on the Polar-4 aircraft, equipped with an instrumental payload (PCASP, DMPS, CPCs, VTDMA, aerosol nephelometer, PSAP photometer, filters, impactor) to study physical (concentration, size), chemical (composition, mixing state of Aitken and accumulation mode particles), and optical (diffusion, absorption) aerosol properties. This leads to first insights of the aerosol influence on cloud formation processes (in particular on ice phase initiation) in arctic clouds. In fact, the chemical composition of cloud condensation nuclei in the arctic troposphere is barely documented and the knowledge about ice initiation is ambiguous: firstly, nucleation mechanisms of cloud particles (ice crystals next to droplets) remain a major and unresolved topic and, secondly, the anthropogenic influence on cloud formation is usually hard to quantify. As mentioned above the Arctic is considered a natural laboratory to study the anthropogenic portion of the aerosol effects, thus, the study will help to answer these questions. Furthermore, the study elaborates sophisticated processing and interpretation methods for the observed data. This leads to an improved characterization of mixed-phase clouds (ice and supercooled water, side by side) by simultaneous restitution of relevant cloud microphysical and optical parameters (e.g. non-sphericity of ice crystals, spatial cloud morphology, etc.) in both cloud phases, including the potential effects of cloud particle shapes (liquid droplets and/or ice crystals of variable shapes) on the scattering properties. The latter results should allow the parameterisation of the scattering phase function as a function of cloud particle shape.

\section{REFERENCES}

Curry, J.A., P.V. Hobbs, M.D. King, D.A. Randall, P. Minnis, G.A. Isaac, J.O. Pinto, T. Uttal, A. Bucholtz, D.G. Cripe, H. Gerber, C.W. Fairall, T.J. Garrett, J. Hudson, J.M. Intrieri, C. Jakob, T. Jensen, P. Lawson, D. Marcotte, L. Nguyen, P. Pilewskie, A. Rangno, D.C. Rogers, K.B. Strawbridge, F.P.J. Valero, A.G. Williams, and D. Wylie, FIRE Arctic clouds experiment, Bulletin of the American Meteorological Society, $81,5-30,2000$.

Gayet, J.F., O. Crépel, J.F. Fournol, and S. Oshchepkov, A new airborne polar nephelometer for the measurements of optical and microphysical cloud properties. Part I: Theoretical design, Ann. Geophys., 15, 451-459, 1997.

Korolev, A.V., J.W. Strapp, G.A. Isaac, and A.N. Nevzorov, The Nevzorov airborne hot-wire LWC-TWC probe: Principle of operation and performance characteristics, J. Atmos. Oceanic Technol., 15 (6), 1495-1510, 1998.

Lawson, R.P., B.A. Baker, and C.G. Schmitt, An overview of microphysical properties of Arctic clouds observed in May and July 1998 during FIRE ACE, J. Geophys. Res., 106, 14.989-15.014, 2001.

Oshchepkov, S., H. Isaka, J.-F. Gayet, A. Sinyuk, F. Auriol, and S. Havemann, Microphysical properties of mixedphase \& ice clouds retrieved from in situ airborne "Polar Nephelometer" measurements, Geophysical Research Letters, 27 (2), 209-212, 2000. 


\title{
AN ESTIMTION ON THE RADIATIVE EFFECTS OF ARCTIC AEROSOLS USING TWO DIFFERENT AEROSOL DATA SETS: A CASE STUDY FOR MARCH
}

\author{
R. TREFFEISEN ${ }^{1)}$, A. RINKE ${ }^{1)}$, M. FORTMANN ${ }^{1)}$, A. HERBER $^{2)}$, K. DETHLOFF $^{1)}$ and \\ T. YAMANOUCHI ${ }^{3)}$
}
${ }^{1}$ Alfred-Wegener-Institut für Polar- und Meeresforschung, Telegrafenberg A43, D - 14473 Potsdam, Germany, e-mail : rtreff@awi-potsdam.de
${ }^{2}$ Alfred-Wegener-Institut für Polar- und Meeresforschung, Bremerhaven, Germany
${ }^{3}$ National Institute of Polar Research Tokyo, Japan

Keywords: Arctic aerosols, radiative effect, physical properties, model input parameters

\section{INTRODUCTION}

The Arctic is a highly sensitive climate region and changes in the Arctic climate and weather may affect the lower latitudes and ocean circulations. So far, the direct radiative effect of Arctic Haze was investigated based on one-dimensional models (e.g., Wendling et al., 1985; Blanchet and List, 1987; Emery et al., 1992; Shaw et al., 1993). All these studies showed a gain of solar radiation by absorption in the atmosphere by $2-20 \mathrm{~W} \mathrm{~m}^{-2}$ (as daily mean value) and were associated with an atmospheric heating rate of 0.1-1.8 $\mathrm{K} \mathrm{day}^{-1}$. Furthermore the shortwave solar net flux at the surface was reduced by $0.2-6 \mathrm{~W} \mathrm{~m}^{-2}$, which resulted in a surface cooling. The calculated magnitudes were strongly dependent on the assumed optical aerosol properties (determined by the concentration, chemical composition, size number distribution, and atmospheric humidity) as well as on the solar zenith angle and surface albedo. However, the evaluation of the climatic direct and indirect effect of Arctic aerosols requires the use of complex three dimensional climate models. The only existing estimation with a global circulation model (Blanchet, 1989) shows a warming at the surface by $1-2 \mathrm{~K}$ for the Arctic region. Due to measurements the Arctic aerosol distribution shows a highly temporal and spatial variation. The coarse spatial resolution of global climate models cannot account for this variation. Therefore, the use of high resolution regional climate models covering the Arctic is recommended in order to study the radiative effect of Arctic aerosols. Regional climate models have a typical horizontal resolution of $15-50 \mathrm{~km}$ and provide the same complexity concerning physical processes as global models. The applied regional climate model HIRHAM (Christensen et al., 1996) is a state-of-the-art regional climate model, well validated and widely used for various Arctic climate applications (e.g., Dethloff et al., 1996; Haugen et al., 1999; Rinke et al., 1999; Christensen and Kuhry, 2000; Rinke et al., 2000; Dethloff et al., 2002; Dorn et al., 2003).

\section{METHOD}

Accurate modelling of solar radiative forcing due to Arctic aerosols requires adequate spectral resolution and treatment of spatial and temporal variability. These needs contrast with the limited measurements of Arctic aerosol characteristics. Two different methods were applied and compared to incorporate aerosol data in an Arctic regional climate model (method 1: aerosol data based on a global aerosol data set, method 2: aerosol data based on Arctic aerosol measurements provided from the Arctic Study on Tropospheric Aerosol and Radiation (ASTAR) campaign performed during March/April 2000 in the vicinity of Spitsbergen). For the transformation via method 2 data of two days were selected with a high and lower aerosol loading in March 2000. These days were considered to be representative for the Arctic spring aerosol loading. 